8.Vogler, J. (2000). Evaluarea în învățământul preuniversitar. Iași: Polirom.

\title{
DIRECȚII DE MODERNIZARE A AUTOEVALUĂRII ȘI EVALUĂRII CONTINUE A REZULTATELOR ELEVILOR. DE LA TEHNOLOGIA INFORMATICĂ LA SISTEME ICT
}

Prof. asistent dr., Stoian Aida Cornelia

Universitatea din Craiova

\section{Rezumatul}

Este nevoie de schimbări majore în procesele de autoevaluare și evaluare continuă a rezultatelor elevilor pentru a face față provocărilor societății actuale.

In acest studiu de cercetare am prezentat abordările actuale ale problematicii evaluative în trecerea ei de la tehnologia informatică la sisteme evaluative de informare și comunicare tehnologică (ICT).

In desfășurarea cercetării am studiat referințele cadrelor didactice cu privire la rolul sistemelor ICT în autoevaluarea elevilor, dar și contribuția evaluării continue automatizate la îmbunătătirea activității de învățare a elevilor.

Ipoteza generală a proiectului de cercetare a urmărit să demonstreze că dacă se conștientizează de către profesorii din învățământul preuniversitar care este rolul sitemelor ICT de autoevaluare și evaluare digitală continuă, atunci se obține adeziunea acestora de a fi implementate și dezvoltate astfel de sisteme de evaluare.

Pentru a studia relaţia dintre variabilele cercetării am aplicat un chestionar, având grup tintă profesorii.

Studiul realizat a avut un impact pozitiv asupra profesorilor respondenti, care au adezionat ideii propuse, fiind încrezători în rolul trecerii de la tehnologizarea informatică a autoevaluării şi evaluării continue a rezultatelor elevilor la implementarea unor sisteme ICT în evaluarea educaţională.

Cuvintele cheie: autoevaluare, evaluare continuă, tehnologie informatică, sisteme ICT de evaluare.

\section{Abstract}

It requires major changes in the processes of self-assessment and continuous assessment of pupils' achievements in order to meet the challenges of contemporary society.

In this research study we presented the current approaches of the evaluative issue in its transition from the informatics technology to evaluative information systems and technology communication (ITC). 
When conducting the research, we have studied teachers' references on the role of the ITC systems in pupils' self-assessment, as well as the contribution of the automated continuous assessment to the improvement of pupils' learning activity.

The general hypothesis of the research project aimed to demonstrate that if secondary school teachers are aware of the role of the self-assessment ICT systems and of continuous digital assessment, then there is obtained their adherence for implementating and developing such systems of assessment.

In order to study the relationship between research variables we applied a questionnaire, with teachers as target group.

The conducted study has had a positive impact on the respondent teachers, who adhered to the proposed idea, being confident in the role of transition from the self-assessment of informatics refurbishment and continuous assessment of pupils' achievement in implementing the ITC systems in the educational assessment.

Keywords: self-assessment, continuous assessment, informatics refurbishment, ITC systems of assessment.

\section{Introducerea}

Una dintre problemele majore cu care se confruntă cercetarea educațională astăzi este reprezentată de platformele de Internet-based. Acestea au rolul de a îmbunătăți activitatea de învățare a elevilor generând noi provocări pentru care trebuie să identificăm soluții. Este necesar pentru sistemul nostru de învățământ să căutăm noi soluții pentru dezvoltarea sistemelor e-learning prin care putem urmări progresul elevilor și evalua în mod automat activitățile practice ale acestora. Astfel, ne propunem studierea problematicii evaluative în trecerea ei de la practica tradițională bazată pe dezvoltarea abilităților elevilor de operare tehnologică la sisteme moderne evaluative de informare și comunicare tehnologică (ICT).

Făcând o incursiune în problematica evaluării, Jean Vogler concluzionează destul de tranșant: universul acesteia nu este nici coerent, nici omogen, nici consensual:

"Nu este omogen și coerent din cauza diverselor curente care îl traversează. Astăzi coexistă două sisteme de evaluare. Primul este tradițional, secular și deci puternic ancorat în mentalitatea actorilor săi. Pe lângă acesta, și oarecum împotriva lui, s-a dezvoltat, spre finalul anilor'60, o altfel de evaluare, pe care am putea s-o numim drept modernă" (Vogler, 2000). 
În plus, teoriile actuale cu privire la educație promovează cu insistență ideea, potrivit căreia, evaluarea modernă trebuie să facă parte integrantă din procesul de învățare, să fie asociată acestuia.

Din perspectiva abordării curriculare și sistemice a procesului de învățământ, este unanim acceptată ideea, potrivit căreia, evaluarea face parte integrantă dintr-un tot, nu trebuie tratată izolat, ci în strânsă corelație cu celelalte activități prin care se realizează procesul de învățământ, cu predarea și învățarea.

Pe de altă parte, metodele, tehnicile și instrumentele de evaluare nu pot fi disociate de celelalte variabile ale evaluării: obiectul evaluării (ce se evaluează), criteriile/obiectivele educaționale, strategiile evaluative etc. Toate acestea sunt ca elementele unui puzzle: pentru a-i înţelege sensul, trebuie să-i ordonezi părţile.

Mergând pe aceleaşi coordonate ale analizei modernizării evaluării în etapa actuală, Constantin Cucoş insistă de asemenea asupra distanţării şi deosebirii fundamentale a acestui proces de controlul clasic al cunoştinţelor sau de măsurarea tradiţională, cu valori de obiectivitate şi concepere a evaluării ca pe o cale de perfecţionare, ce presupune o strategie globală a formării: „În accepţiune modernă, evaluarea nu (mai n.n.) trebuie înţeleasă ca o etapă supraadăugată sau suprapusă procesului de învăţare, ci constituie un act integrat activităţii pedagogice." (Cucoş, 2008).

Evaluarea interesează din ce în ce mai puţin din perspectiva măsurătorilor şi a rezultatelor şi din ce în ce mai mult din punct de vedere al procesualităţii sale.

"Evaluarea şcolară este concepută din ce în ce mai mult ca parte integrate a procesului de învăţare şi jalon al acestuia" (Abernot, 1996, p.5). În ultimele decenii pedagogia a acordat o mare atenţie studiului conceptul de evaluare "formativă", care atribuie evaluării un rol important în formarea elevului, analizând progresul competenţelor sale.

Evaluarea modernă marchează evoluţia de la rolul de control al cunoştinţelor dobândite la cea de evaluare a rezultatelor învăţării şi a proceselor implicate, componente de bază ale structurii activităţii didactice. 
Ioan Cerghit afirmă că evaluarea este o "ştiinţă a valorii"(p.287), ce face referire la un sistem de judecăţi de valoare. Astfel, " învăţământul îşi declară în mod clar priorităţile pentru un anumit sistem de valori, îşi justifică opțiunile şi preferinţele în raport cu anumite valori traduse în obiective. Aceste valori trebuie să şi le însuşească şi să şi le interiorizeze elevul, să le integreze în structurilie sale de cunoaştere şi simţire, în conduita personală."( Cerghit, p.288, în Potolea, D.; Manolescu, M., 2005).

Evaluarea, alături de predare şi învăţare, trebuie privită ca o singură unitate la care ne raportăm: "Trebuie să vorbim despre evaluare în termeni de procese. În locul termenului consacrat de evaluare trebuie să vorbim de "activitate evaluativă", de "evaluare în acţiune, în desfăşurare." (Manolescu, 2004).

În acest sens, evaluarea devine un demers axat pe implicarea activă a elevului în învăţare, pe procesele cognitive ale acestuia, pe reglare şi autoreglare a cunoaşterii, desconsiderându-şi rolul de simplu instrument folosit în măsurarea şi controlul procesului didactic.

Dar prelucrarea înseamnă procesare. Rezultatul procesării informaţiei este formarea de capacităţi şi competenţe.

Transformarea competenţei în finalitate a procesului educational şi în "obiect al evaluării" reprezintă rezultatul deplasării accentului dinspre produsele învăţării spre procesele implicate în activitatea de învăţare. Obiectul evaluării poate fi definit ca fiind realitatea educaţională concretizată în procesul şi produsul învăţării, supusă atenţiei evaluatorului, în vederea măsurării şi aprecierii. Prin evaluare, se emit judecăţi privind valoarea procesului şi produsului învăţării realizată de elev.

Autoevaluarea - este evaluarea efectuată de către elev asupra a ceea ce a realizat şi/sau asupra comportamentului său. Ajută elevii să-şi dezvolte capacităţile de autocunoaştere, să-şi valorizeze atât cunoştinţele cât şi atitudinile şi comportamentele.

"Autoevaluarea este posibilă şi necesară întrucât serveşte cunoaşterii (perceperii) de sine (autocunoaşterii) şi dezvoltării conştiinţei de sine (autoconştiinţei), aspecte esenţiale ce vor da posibilitatea, cu timpul, fiecăruia să descopere sensul propriei valori, premisă necesară oricărei depăşiri; o disponibilitate privită în 
perspectiva educaţiei permanente, care presupune angajarea individului nu numai în procesul propriei formări, ci şi în acţiunea de evaluare a propriei formări pentru a deveni capabili de autoperfecţionare." (Cerghit, 2005, p. 312).

Important este întreg contextul situațional care acționează asupra formării elevului. Evaluarea trebuie să fie centrată pe elev și implicit, procesul de învățare trebuie adaptat nevoilor de formare ale elevului. Dacă analizăm metodele și tehnicile de învățare digitală, evaluarea ca proces devine importantă și un instrument de bază în procesul de învățare (Carswell et al., 2000; Morgan et al., 2002; Schrum et al., 2007).

Alegând formele de evaluare, școala este cea care determină învățarea elevului adaptând conținuturile ritmului de învățare al elevilor. Interacțiunea online dintre școală și elevi determină creșterea eficienței procesului de evaluare urmărind atingerea nivelului obiectivelor anterioare. (Robles-Gómez et al., 2011; Agudo et al., 2011).

Printr-un sistem de evaluare automatizată profesorii pot realiza o înregistrare mai amănunțită a progresului școlar al fiecărui elev și al unui număr cât mai mare de elevi.

Astfel sunt evaluate activitățile practice ale elevilor și identificate lipsurile acestora.

Acest sistem de evaluare vine în sprijinul profesorilor prin precizarea punctelor slabe din procesul de învățare din rapoartele pe care le generează. Practicile evaluative nu pot fi posibile într-un sistem tradițional de evaluare care se bazează pe chestionare, întrebări cu răspunsuri închise sau deschise și ignoră activitățile practice.

Informațiile furnizate de sistemele informatice de evaluare pot fi concentrate pe adaptarea conținutului și resurselor la particularitățile individuale ale elevilor. Elevii pot obține astfel un feedback al activităților transversale desfășurate, care nu este prezent în evaluarea tradițională ce se bazează pe interpretarea rapoartelor fiecărui domeniu de activitate.

Integrarea computerului în curriculum școlar este un proces complex în continuuă modernizare de la perceperea computerului ca resursă materială care îmbunătățește activitatea profesorului și a elevilor 
la integrarea computerului în învățare și evaluare pentru formarea și dezvoltarea competențelor.

Platformele curente de învățare sunt bazate pe raportul între elevi și conținuturi. Acestea au rolul de a centraliza învățarea, bazânduse pe conținuturi și de a promova metode de evaluare centrate pe conținuturile teoretice. În cazul acesta elevilor le poate fi verificat imediat nivelul de cunoștiințe prin itemi cu alegere multiplă sau exerciții de asociere a conceptelor (Douce et al., 2005)

Prin urmare, folosirea $\mathrm{cu}$ succes a tehnologiilor informatice necesită noi abilități care nu pot fi realizate într-un mediu tradițional de educație. Este nevoie de interacțiune, un acces și o utilizare care să nu fie condiționată de timp și spațiu.

Este nevoie de un program educațional care să execute evaluarea continuă a procesului de evaluare a progresului înregistrat de elev și să indice care este drumul pe care trebuie să îl parcurgă pentru a atinge pragul de eficiență.

În acest sens, utile sunt sistemele avansate de gestionare a autoevaluării și evaluării continue, fiind înțelese ca un set de servicii web. Aceste aplicaţii orientate spre anumite servicii pot fi considerate cele mai noi descoperiri în platformele de informatizare şi comunicare tehnologică.

În proiectul de cercetare, ne-am propus ca obiective:

1.Studierea referințele cadrelor didactice din învățământul preuniversitar cu privire la rolul sistemelor ICT în autoevaluarea elevilor.

2. Analiza contribuției evaluării continue automatizate la îmbunătățirea activității de învățare a elevilor în opinia cadrelor didactice

Ipoteza generală a proiectului de cercetare a urmărit să demonstreze că dacă se conștientizează de către profesorii din învățământul preuniversitar care este rolul sitemelor ICT de autoevaluare și evaluare digitală continuă, atunci se obține adeziunea acestora de a fi implementate și dezvoltate astfel de sisteme de evaluare. 
Din această ipoteză generală derivă următoarele ipoteze specifice:

1.Dacă profesorii identifică rolurile și funcțiile autoevaluării ICT, atunci se poate obține adeziunea acestora la implementarea sistemelor ICT de autoevaluare

2.Dacă profesorii analizează contribuția evaluării continue ICT, atunci vor identifica beneficiul acestor sisteme ICT la îmbunătățirea activității de învățare a elevilor.

\section{Metodologia}

Esantionul

Eșantionarea cercetării a fost de tip stratificat, cuprinzând 328 de profesori. Lotul de subiecți este dispersat la nivel național în 19 școli aflate în localitățile: Craiova, București, Alexandria, Bistreț, Filiași, Dăbuleni, Bechet și Calafat. Alegerea școlilor și localităților a vizat echilibrarea balanței între școlile din mediul rural și cele din mediul urban.

\section{Metode}

Am folosit ca metode de cercetare metoda analizei pe baza chestionarului, aplicând un chestionar profesorilor din învățământul preuniversitar.

Ne-am propus ca prin metoda anchetei pe baza chestionarului adresat cadrelor didactice să surprindem referințele cadrelor didactice din mediul urban și rural în privința rolului sistemelor ICT în autoevaluarea elevilor, dar și implicațiile evaluării continue la progresul în învățare al elevilor.

\section{Instrumente}

Chestionarul a fost instrument de bază al cercetării noastre. În vederea prelucrării datelor referitoare la eșantionul cercetării am optat pentru programul IBM.SPSS, varianta 21.

Am obținut pentru chestionarul aplicat cadrelor didactice un coeficient Alpha Cronbach în formă brută cu o valoare 0,856, iar în formă standardizată (formă bazată pe corelații) având rezultatul 0, 954.

\section{Rezultate}


Referințele cadrelor didactice cu privire la rolul sistemelor ICT în practicarea autoevaluării de către elevi

Studiind opinia cadrelor didactice despre practicarea autoevaluării ICT de către elevi: 77,1\% consideră că ar putea fi o bună practică, iar 22,9\% nu sunt de acord.

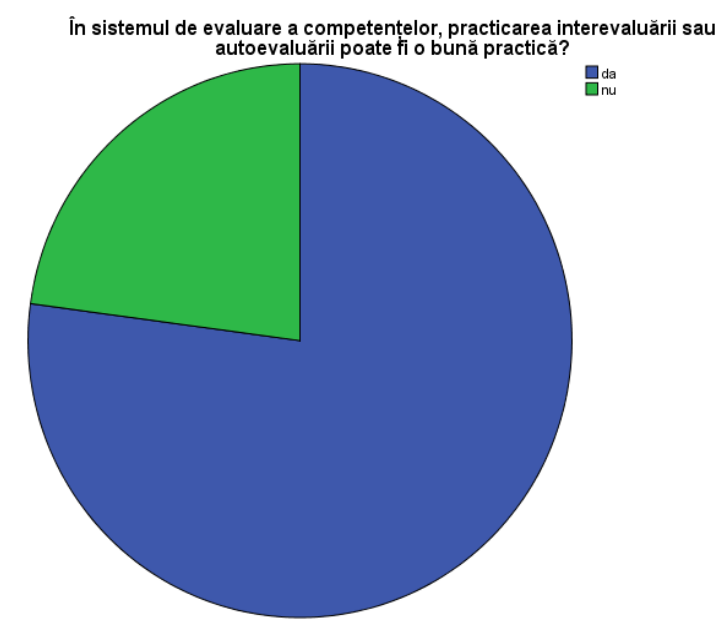

Figura1. Reprezentarea opiniei cadrelor didactice despre autoevaluarea ICT

Referitor la rolurile pe care le poate îndeplini autoevaluarea ICT, profesorii au identificat: $89 \%$ că poate îndeplini rolul de creștere a unității de timp pentru adaptarea dinamică a elevilor în vederea formării capacității de evaluare/autoevaluare, 7,3\% nu recunosc această funcție, iar 3,7\% sunt fără opinie.. 


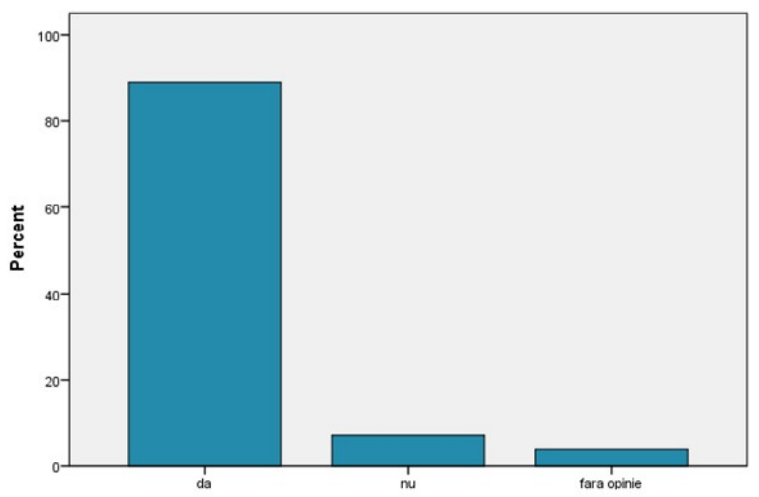

Figura 2. Reprezentarea opiniei cadrelor didactice despre rolul de creștere a unității de timp pentru adaptarea dinamică a elevilor în autoevaluarea ICT

Dintre cadrele didactice $75,9 \%$ menționează că autoevaluarea ICT poate reprezenta o verificare imediată a răspunsului elevilor, 22,3\% nu recunosc această funcție, iar 1,8\% nu au nicio opinie în acest caz.

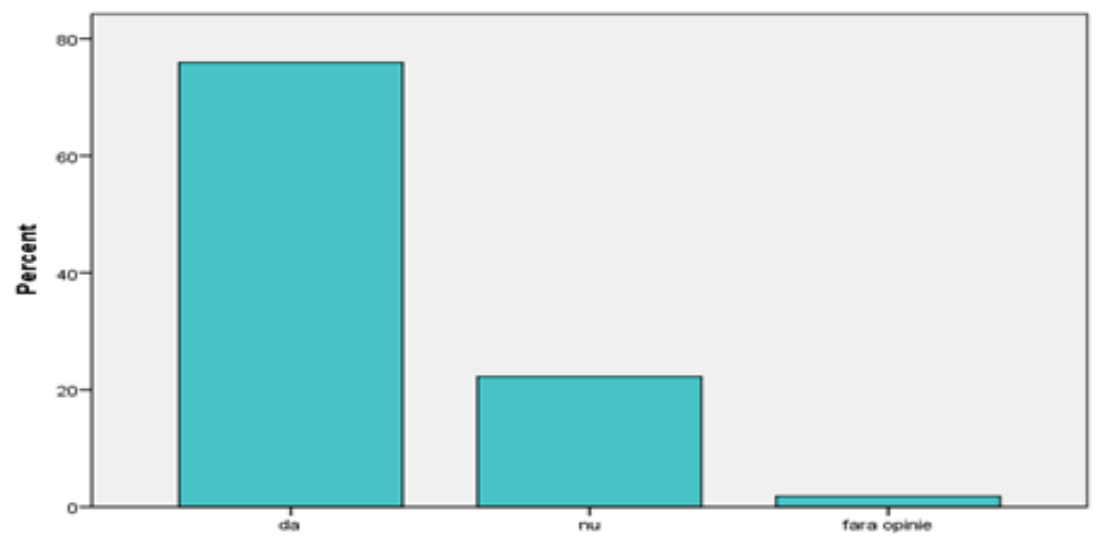

Figura 3. Autoevaluarea ICT poate reprezenta o verificare imediată a răspunsului elevilor

Referindu-ne la identificarea altor roluri pe care le poate îndeplini autoevaluarea ICT, cadrele didactice au răspuns într-un număr relativ redus, din 328 subiecți chestionați au fost doar 45 de respondenți, 
înregistrând un scor de 13,7\%. Rolurile și funcțiile autoevaluării la care au făcut referire sunt:

- dezvoltarea competențelor transversale ale elevilor;

- formarea capacității de comparare, raportare la o referință, standard;

- corectare a ideilor eronate;

- feedback pentru profesori;

- stimulare a curiozității;

- dezvoltarea obiectivității;

- asigurarea transparenței notării, evitarea suspiciunilor de subiectivism în evaluare;

- conștientizarea nivelului la care se află elevul la un moment dat.

Efectele pozitive ale unui sistem ICT de autoevaluare sunt reprezentate de consecința imediată de verificare a răspunsurilor, timpul alocat răspunsului fiind redus la minim. Evaluarea automatizată a activităților practice reduce timpul petrecut în realizarea activităților practice, crescând timpul pentru adaptarea dinamică a elevilor. Aceste sisteme permit evaluarea liberă a progresului elevilor în învățare și fortificarea încrederii, astfel încât elevii să continue să învețe.

Studiul contribuției evaluării continue ICT la îmbunătățirea activității de învățare a elevilor

$\mathrm{Cu}$ scopul dezvoltării la elevi a unor conduite de tip autoinițiere, automotivare, automonitorizare, autoevaluare și autoreglare a învățării am solicitat cadrelor didactice să precizeze în ce măsură un sistem ICT de evaluarea continuă contribuie la îmbunătățirea activității de învățare, dezvoltarea activității reflexive, de autoanaliză și autoevaluare a propriilor rezultate, cultivarea motivației pentru învățare, dezvoltarea responsabilității profesionale față de propriile rezultate ale învățării.

Respondenții profesori consideră că sistemele ICT de evaluarea continuă contribuie la îmbunătătirea activității de învățare, stabilind următoarea clasificare: $73,8 \%$ în foarte mare măsură, $17,1 \%$ în mare măsură, 5,5\% nivel moderat, 1,8\% în mică măsură, 1,8\% fără opinie. 


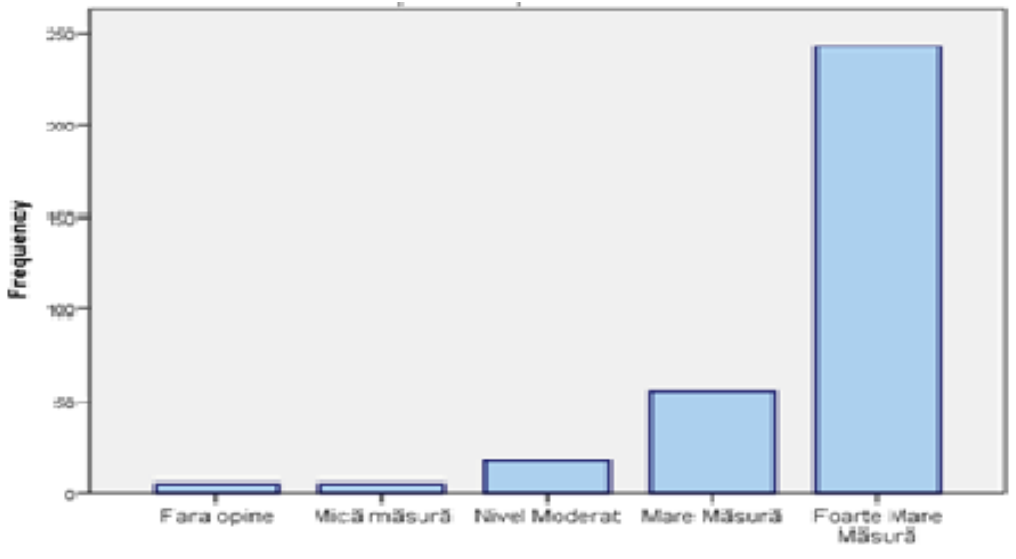

Figura 4. Reprezentarea opiniei cadrelor didactice despre relația evaluare continuăînvățare continuă

Referitor la contribuția evaluării continue la dezvoltarea activității reflexive, de autoanaliză și autoevaluare a propriilor rezultate obținute de elevi, respondenții-cadre didactice au optat pentru următoarea ierarhie: $37,2 \%$ în foarte mare măsură, 36,9\% în mare măsură, 18,6\% nivel moderat, 5,5\% în mică măsură și 1,8\% fără opinie; iar respondenții-elevi: 34,1\% în foarte mare măsură, 26,9\% în mare măsură, 15,4\% nivel moderat, 21,6\% în mică măsură, 1,6\% deloc, $0,3 \%$ fără opinie.

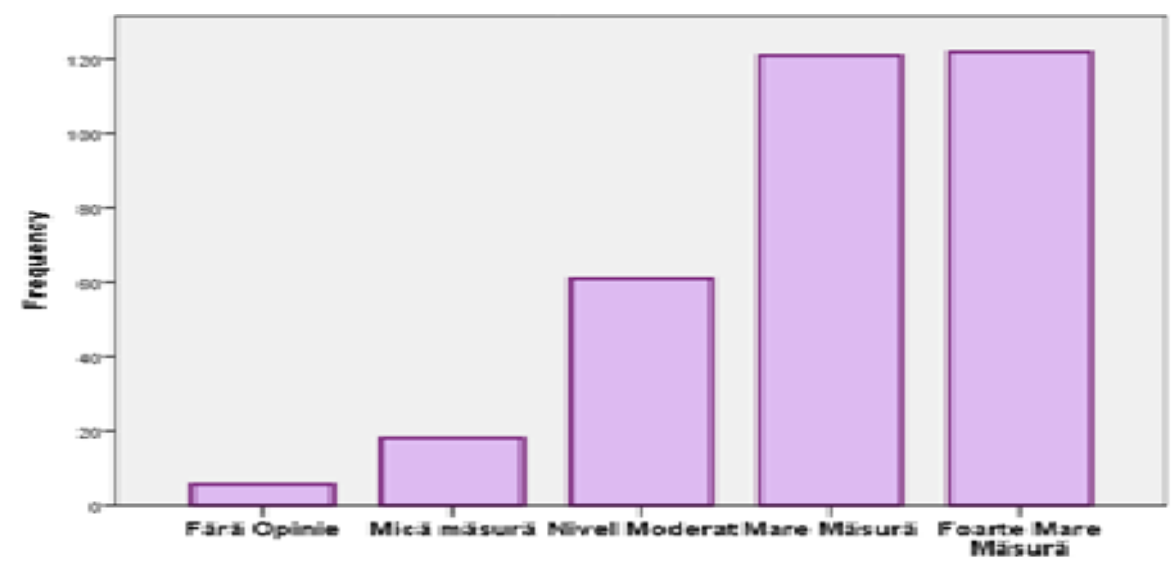


Figura 5. Reprezentarea opiniei cadrelor didactice despre relația evaluare continuădezvoltarea activității reflexive, de autoanaliză și autoevaluare

Pentru a determina gradul în care evaluarea continuă cultivă motivația pentru învățare a elevilor, cadrele didactice au răspuns: 52,1\% în foarte mare măsură, 22,3\% în mare măsură, 16,5\% nivel moderat, 7,3\% în mică măsură și 1,8\% fără opinie; iar respondenții-elevi: 36,7\% în foarte mare măsură, $27,9 \%$ în mare măsură, 27,9\% nivel moderat, $3.9 \%$ în mică măsură, 2,3\% deloc, 1,3\% fără opinie.

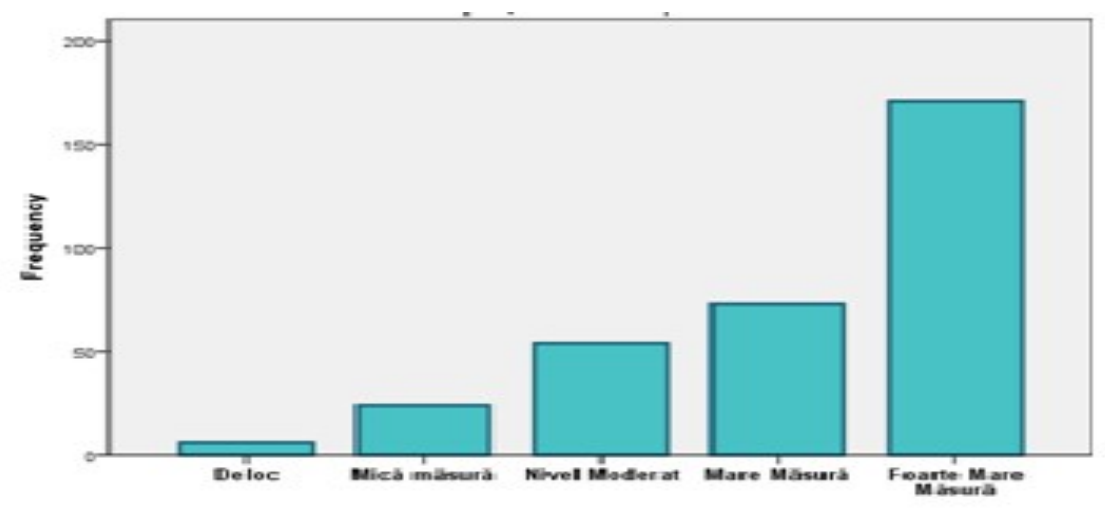

Figura 6. Reprezentarea opiniei cadrelor didactice despre relația evaluare continuămotivație pentru învățare

Referitor la contribuția evaluării continue asupra dezvoltării responsabilității profesionale față de propriile rezultate ale elevilor, cadrele didactice au răspuns: $44,5 \%$ în foarte mare măsură, $31,7 \%$ în mare măsură, 9,1\% nivel moderat, $11,0 \%$ în mică măsură și 3,7\% fără opinie; iar respondenții-elevi: 31,8\% în foarte mare măsură, $26,6 \%$ în mare măsură, 36,4\% nivel moderat, 2,6\% în mică măsură, 2,0\% deloc, 0,7\% fără opinie. 


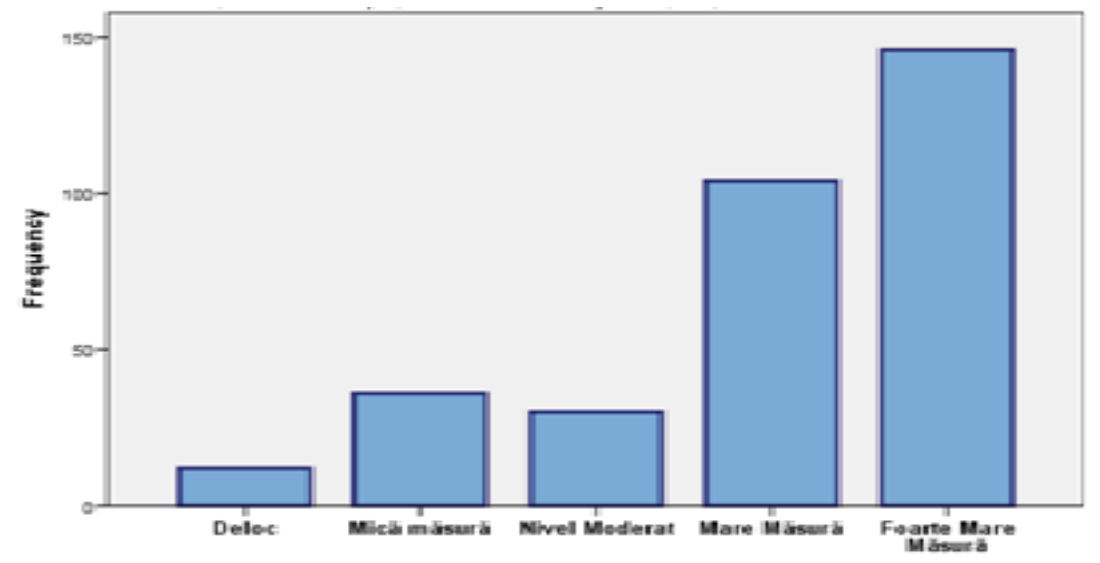

Figura 7. Reprezentarea opiniei cadrelor didactic despre relația evaluare continuădezvoltării responsabilității profesionale față de rezultate ale elevilor

Analizând măsura în care profesorii determină rolul evaluării continue ICT asupra dezvoltării unor comportamente de tip autoinițiere și automotivare, observăm importanța pe care respondenți o acordă dezvoltării practicilor de evaluare continuă considerând că aceasta contribuie în foarte mare măsură la îmbunătățirea activității de învățare, dezvoltarea activității reflexive, cultivarea motivației pentru învățare, dezvoltarea responsabilității față de propriile rezultate.

Utilizatorii unui sistem de evaluare ICT pot evalua progresul elevilor într-un timp scurt, având rezultate immediate și la un prag sporit de încredere care determină motivarea elevilor de a se implica în învățare, de a desfășura independent activități practice. Astfel, aprecierea rezultatelor elevilor este automat transmisă elevilor, nefiind necesar ca aceștia să aștepte pentru a obține evaluarea rezultatelor finale. Un astfel de sistem de evaluare automatizată are un rol important în dinamizarea progresului elevilor și evaluarea mult mai rapidă și justă a activităților practice ale acestora.

\section{Concluzii}

Sintetizând, putem preciza următoarele aspecte:

Lucrarea prezintă câteva contribuţii personale: 
- Abordarea dimensiunilor și rolurilor sistemelor ICT de evaluare a rezultatelor elevilor pentru a gestiona autoevaluarea și evaluarea continuă a progresului elevilor;

- Aducerea în discuție a unui concept mai puțin studiat în literatura de specialitate, de informatizare și comunicare tehnologică a activităților de autoevaluare și evaluare continuă, determinând criterii ale evoluției sistemelor ICT de evaluare.

Evaluarea continuă și autoevaluarea rezultatelor elevilor au nevoie de dezvoltarea unor sisteme complexe care să implice diverse tehnologii informatice (fișierele de configurare, baze de software sau unităti de implementare), precum și de viteza de software-lor sau evoluția sistemelor de operare. Prin urmare, se constată ca fiind de maximă importanță implementarea unei soluții generice, care să dezvolte competențe transversale elevilor.

Este nevoie în evaluare de mutarea accentului de la dezvoltarea competențelor elevilor de a utiliza tehnologia informatică în evaluare la dezvoltarea competențelor transversale de informatizare și comunicare tehnologică în cadrul unor sisteme automatice de evaluare. Aceste sisteme ICT trebuie să cuprindă activităti de evaluare organizate sistematic, riguros descrise, să detalieze practicile reale de operare, să stabilească criteriile de evaluare, pe care să le definească. De asemenea trebuie să cuprindă fișere de configurare și modele care urmează să fie aplicate în evaluarea elevilor.

Principalele probleme deschise sunt: aprofundarea problematicii sistemelor ICT de evaluare; extinderea cercetărilor în domeniul practicilor evaluative bazate pe aceste sisteme; susținerea motivației pentru învățare a elevilor ca implementării și dezvoltării informatizării și comunicării tehnologice a evaluării școlare.

Lucrarea prezintă ca și limite ale cercetării: reticența unor cadre didactice de a oferi răspunsuri juste; confuzia științifică a cadrelor didactice între dezvoltarea competențelor elevilor de a utiliza calculatorul în activitatea de evaluare și sistemele ICT de evaluare a rezultatelor elevilor.

\section{Bibliografie:}


ABERNOT, Y. (1998). Les méthodes d'évaluation scolaire. Nouvelle edition. Paris: DUNOD

CARSWELL, L., THOMAS, P., PETRE, M., PRICE, B., \& RICHARDS, M. (2000). Distance education via the Internet: The student experience. British Journal of Educational Technology, 31(1), 29-46

CUCOŞ, C. (2008). Teoria şi metodologia evaluării. Bucureşti: Editura Polirom

DOUCE, C., LIVINGSTONE, D., \& ORWELL, J. (2005). Automatic test-based assessment of programming: A review. Journal on Educational Resources in Computing, 5(3), 1-13.

MANOLESCU, M. (2004). Activitatea evaluativă între cogniție și metacogniție. București: Editura Meteor

MORGAN, CH. \& O'REILLY. (2002). Assessing Open and Distance Learners. London, United Kingdom: Kogan

POTOLEA, D., MANOLESCU, M. (2005). Teoria și practica evaluării-curs universitar. În Proiectul pentru Învățământ Rural. Bucureşti. Preluat pe 24.02.2012 de pe http://www.scribd.com/doc/148035655/Teoria-Si-Practica-Evaluarii.

ROBLES-GÓMEZ, A., TOBARRA, L., ROS, S., HERNÁNDEZ, R., CAMINERO, A. C., PASTOR, R., \& CASTRO, M. (2011, April). Proposal of an Auto-Evaluation Framework for the Learning of Network Services. In A. Y. Al-Zoubi et al. (Eds.), Global Engineering Education Conference (EDUCON), 2011 IEEE (pp. 392-396). Amman, Jordan: IEEE Education Society.

SCHRUM, L., BURBANK, M. D, \& CAPPS, R. (2007). Preparing future teachers for diverse schools in an online learning community: Perceptions and practice. Internet \& Higher Education, 10(3), 204-211

VOGLER, J. (2000). Evaluarea în învăţământul preuniversitar. Iaşi: Editura Polirom

\section{Academical and professional profile:}

Stoian Aida Cornelia works for the Departament for Teachers Preparation, University of Craiova. Her field of work is as assistance teacher Ph. D.

Email: aidda1977@yahoo.com 